\title{
The Stages of Tri ning Danu Tourism Destination Development Based on Tourism Capital
}

\author{
I Nyoman Sunarta, I Nyoman Sukma Arida, I Made Adikampana, and Saptono Nugroho \\ Tourism Destination Program Study, Tourism Faculty \\ Udayana University \\ Denpasar, Bali, Indonesia \\ cairns54@yahoo.com, sukma.arida@gmail.com, adikampana@unud.ac.id, snug1976@gmail.com
}

\begin{abstract}
This article aims to determine the life cycle of tourist destinations in three lakes: Beratan, Buyan, and Tamblingan or referred to as Tri ning Danu, based on tourism capital. This study was conducted considering the research about the lake-based tourism is still very limited, especially in Indonesia. The analysis was carried out using the model of the Tourist Area Life Cycle (TALC) introduced by Butler and the conception of tourism capital inspired by Bourdieu. The integration of both produces a profile of the position or stage of Tri ning Danu tourist destination development more adequately. This approach is relatively new as a breakthrough effort to get rid of conventional reports on the destination developments that generally rely solely on TALC. It is expected that with the added of tourism capital variable will get a more comprehensive view of destination development stage. The results of the stage of Tri ning Danu tourist destination development based on the tourism capital, as follows: Consolidation Stage for Beratan Lake, Involvement Stage for Buyan Lake, and Exploration Stage for Tamblingan Lake.
\end{abstract}

Keywords: destination stage, TALC, tourism capital, Tri ning Danu.

\section{INTRODUCTION}

This work is an academic effort on the increasingly complex issues of contemporary tourism, linked to the discourse of tourism impacts on environmental, sociocultural and socioeconomic dimensions, in the area based on lake tourism. This is considering the study of lake-based tourism is still very rare, especially in Indonesia. In particular, the focus will be applied in the Bedugul Tourism Area which has three lakes (Beratan, Buyan, Tamblingan) termed Tri ning Danu. This article aims to determine the life cycle of tourism destination areas in the Tourism Attractions of Beratan Lake, Buyan, and Tamblingan based on tourism owned capital.

\section{METHOD AND PROCEDURES}

The analysis has utilized the conception of Tourist Area Lifecycle (TALC) from Butler and the conception of capital from Bourdieu. The integration of both produces a profile of the position or level tourism development Tri ning Danu more adequately. This approach is relatively new as a breakthrough effort to get rid of conventional reports on the tourism development that generally relies solely on TALC.
It is expected that with the added of capital variable will get a more comprehensive picture of development level of a tourism destination.

\section{RESULT}

\section{A. Tri ning Danu Tourism Capital}

Tourism capital is a resource owned by a tourism destination to be the basis of attraction and strength in management. This conception was developed with reference to Pierre Bourdieu's idea of the capital. Capital is resources that enable a person or a group to have the ability to gain opportunities in life. There are several types of capital, such as cultural capital (education and family background), economic capital (money), and social capital (network), and symbolic capital (influence ability). Capital can be obtained if it has the right habitus of its life [1].Furthermore, in this paper modify the notion of capital from Bourdieu into tourism capital. Tourism capital can be identified into five types, namely: physical, social, cultural, economic, and symbolic. In the context of this research, the identified tourism capital is related to the ownership of these resources by local communities.

1) Physical tourism capital

This type of capital is a natural resource that can be created 
as a tourist attraction.

2) Social tourism capital

Social capital in tourism is the quantity and quality of institutions and networks owned by a tourism destination. Institutions and networks can be formal/informal or in the form of internal/external. That mean, by having a wide social network (quantitative) and deep (qualitative) then a particular tourism destination will be relatively more capable in maintaining its existence, related to its management and development.

3) Cultural tourism capital

Cultural capital is a kind of resources owned by a tourism destination associated with the knowledge and technology exclusively. In the discourse of contemporary cultural studies known as local wisdom and local genius.

4) Economic tourism capital

Economic capital is related to ownership of material resources owned by a destination.

5) Symbolic tourism capital

Symbolic resources are assets in the form of power/power possessed by dominant actors (individuals or institutions) in a destination. Generally, this type of capital is the result of the accumulation of the four other capitals.

Based on observations and interviews, has collected data related to the distribution and type of capital owned by three lake tourism destination.

1) Lake Beratan

Lake Beratan has complete tourism resources, comprised of environmental, social, cultural, economic, and symbolic resources. Local people in this context have high tourism capital.

a) Physical resources

The main environmental resource owned by Beratan Destination is the lake with its main tourist attraction is Pura Ulun Danu. In addition, the lake is used as a base for water tourism, such as parasailing, canoeing, and jetski. Another environment-based attraction is a beautiful landscape scene and a cool air. In the eastern part of Lake Beratan there is a mountain called Mount Catur with a height of 2,098 meters (local people call it "Pucak Mangu") as a representative place for hiking and tracking activities.

b) Social resources

The Candikuning Village community as a representation of the local community that manages Lake Beratan, plays an active role in the Bedugul Tourism Object Management Board. Through this institution, local people are able to participate in tourism practices in Lake Beratan by participating in decision making and sharing of tourism profits.

c) Cultural resources

Cultural wisdom owned by local communities associated with Beratan Lake breeding. For people, the lake is not just a mere physical space that can be empirically sensed (sekala), but has a spiritual meaning (niskala). These forms of reverence are represented through the construction of the shrine (Pura) and the administration of rituals. From this cosmology that gave birth to local genius and local wisdom which became the basis of tourism in the realm of Lake Beratan. That is, tourism practices that are organized depart from local cultural practices related to the glorification of Lake Beratan. Attractions are presented to tourists is a mix between the physical space of the lake with many temples and shrines that surround it, along with ritual activities of local communities in order to glorify the lake. At least, there are 16 identified shrines at Lake Beratan.

d) Economic resources

Economic resources related to ownership of material resources owned by stakeholders in Lake Beratan. The main economic resources are the landscape of the lake along with the culture owned by the local community which is used as the base of tourist attraction. In addition, many established accommodation and restaurant businesses in order to support existing tourism. Along with the development of tourism, began to bloom vegetable farming. For the case of this destination, the ownership of the economic capital of tourism is dominated by the Candikuning Traditional Village. They carry the concept of "business-religious", which means $80 \%$ of tourism income is used to finance custom and religious needs.

e) Symbolic resources

In the development of tourism management in Lake Beratan, consists of three stages:

- Controlled by individuals (before 1999)

- Controlled by the Management Board (1999 to 2009)

- Mastered by Candikuning Traditional Village (2009 to present).

The mastery of tourism management by Candikuning Traditional Village makes them have the ability to accumulate tourism capital consisting of physical capital, social capital, cultural capital, and economic capital. The mastery of the four types of capital makes local people have symbolic capital, which has the meaning of ability in determining tourism practices that are held, or by other terms have power over the discourse of Beratan Lake tourism. They define the mechanisms of tourism practice, in terms of defining what tourists can and should not do, share the benefits of tourism, and the mechanisms of tourism organization.

2) Lake Buyan

a) Physical resources

The physical tourism resources owned by this destination are lakes and their natural landscape as the main tourist attraction. In addition, there are agricultural and fishery activities. Physical resources within the context of tourism practices are accessed by BKSDA (natural resource conservation center) and 
Pancasari villages through the Sadar Wisata Group (Pokdarwis).

b) Social resources

The government has designated the area of Lake Buyan to be a Natural Park) area, not only in the lake area but extending to the lake area of Lake Tamblingan. The area of this Nature Tourism Park is more than 1,700 hectares not including the forests on the edge of the lake. If the calculated area of forest conservation reaches 15,000 hectares, most of which is wilderness and only a few forest park area.Mastery of management by BKSDA. Pancasari Village awareness group can be said to be idle because the failure of the internal actors to consolidate.

c) Cultural resources

Cultural resources owned by local people can be used as cultural attractions that are often performed, which is held when there are religious ceremonies. Traditional arts attractions such as sacred dance arts, among others: Baris Gede Dance, Baris Tojor dance, Rejak Dance and Puppet. Art of gamelan like Gender Wayang, Gong Gede, and Gong Kebyar and Mebleganjur. The art of sounds such as Kekawin, Kidung and Geguritan are used when there are traditional ceremonies or religious ceremonies.

d) Economic resources

Tourists can enjoy the beauty of the natural landscape of Lake Buyan, whether viewed from afar, or through it by renting a boat. Campsite Earth Area can also lure in the surrounding lake. If you want to spend the night in this lake, tourists can camp in Campsite Earth Area. There is a facility in this Campsite. The entire area on the outskirts of this lake is a forest, only a small area on the edge of the lake that is used by residents around some agricultural areas. Residents around utilize the existing land by planting some vegetables and fruits that can live in cold areas such as strawberries, cabbage, and others. Tourists who want to enjoy the natural beauty of this lake, you can take advantage of the Campsite Earth Area located in the south of this lake.

e) Symbolic resources

The actor who has symbolic resources in Buyan Lake tourism area is BKSDA. As an institution that represents the state in conservation at Buyan and Tamblingan nature park, they have legal domains over the domain.

3) Lake Tamblingan

a) Physical resources

The physical tourism resources owned by this destination are lakes and their natural landscape as the main tourist attraction. In addition, there are agricultural and fishery activities. Physical resources within the context of tourism practices are accessed by BKSDA and local communities through the Sadar Wisata Group (Pokdarwis). b) Social resources

The government has designated Lake Buyan and Tamblingan areas to be Nature Park area, not only in the lake area but extending to the lake area of Tamblingan. The area of this Nature Tourism Park is more than 1,700 hectares not including the forests on the edge of the lake. If the calculated area of forest conservation reaches 15,000 hectares, most of which is wilderness and only a few forest park area.Mastery of management by BKSDA. Local communities work with BKSDA and investors, with support from the Government of Buleleng District.

c) Cultural resources

Cultural resources owned by local people can be used as cultural attractions that are often performed, which is held when there are religious ceremonies. Traditional arts attractions such as sacred dance arts. The art of sounds such as Kekawin, Kidung, and Geguritan are used when there are traditional ceremonies or religious ceremonies.

d) Economic resources

When compared with other lakes in Bali, Lake Tamblingan is the smallest because it only has a surface area of $1.15 \mathrm{~km}$ square. Nevertheless, it offers a very beautiful view. Besides the atmosphere was still natural. No motorboats found in this lake. If you want to get around the lake, visitors can rent a small boat owned by residents. The name Tamblingan comes from the word 'tamba' or medicine and the word 'elingang' or spiritual ability. Historically, the water in this lake used to be used by saints to cure disease outbreaks that hit the area. Since then, in this lake area stood many temples, whose names as mentioned earlier. The blend of natural and cultural landscapes into a tourist attraction is offered, thus becoming an economic resource for local communities.

e) Symbolic resources

The actor who has symbolic resources in the tourism area of Lake Tamblingan is BKSDA. As an institution that represents the state in conservation at Buyan and Tamblingan nature park.

\section{B. Development Stage of Tri ning Danu Tourism Based on Tourism Capital}

The tourism life cycle refers to the concept of TALCS (Tourist Area Life Cycle Stage) introduced by Butler [2], can be described as follows:

Stage 1.Exploration.

Tourism potential is in the identification stage and shows the destination has the potential to be developed into a tourist attraction or destination because it is supported by natural beauty that is still natural, natural tourist attraction is still very original, on the other side there has been tourist visits in small quantities and they are still free can meet and communicate and interact with local people. This characteristic is enough to be used as the reason for the 
development of a region into a destination or a tourist attraction.

Stage 2.Involvement.

At the stage of engagement, local people take the initiative by providing various services to tourists who are beginning to show signs of improvement over periods. Communities and local government have started to socialize or advertising on a limited scale, on a season or month or a particular day for example on school holidays tourists visit in large numbers, in this condition the local government took the initiative to build tourism infrastructure but still in scale and limited number.

Stage 3. Development

At this stage, there has been a large number of tourist visits and the government has dared to invite national or international investors to invest in tourist areas that will be developed. Multinational National Company (MNC) has operated and tend to replace existing local companies, meaning small businesses managed by local residents are getting left out because of the demands of global tourists expecting better quality standards. Tourism organizations are beginning to take shape and carry out their functions, especially promotive functions that are carried out jointly with the government so that foreign investors are interested and choose the existing destination as their investment destination.

Stage 4. Consolidation

At this stage, the tourism sector shows dominance in the economic structure of a region and there is a tendency of the dominance of international networks to strengthen its role in the tourist area or destination. Visits of tourists still show a fairly positive increase but there has been price competition among similar companies in the tourism industry in the region. The role of local government began to diminish so that consolidation needed to reorganize, and balancing roles and duties between the public and private sectors.

Stage 5. Stagnation

At this stage, the highest number of visits has been reached and some periods show a stagnant trend. Although the number of visits is still relatively high but the destination is actually no longer attractive to tourists. Tourists who still come are those who include guest repeaters or those who are classified as loyal tourists for various reasons. The promotional programs are very intensive but the effort to bring in tourists or new customers is very difficult. Destination management exceeds carrying capacity resulting in negative things about destinations such as environmental damage, rampant crime, price competition in the tourism industry, and cultural degradation of local communities.

Stage 6. Decline/ Rejuvenation.

After stagnation, there are two possibilities that can occur in a destination. If efforts are not made to exit from the stagnation stage, the possibility of destinations is abandoned by tourists and they will choose other destinations that are considered more attractive. The destination is only visited by domestic tourists and even then only crowded on weekends and holidays only. Many tourist facilities have been transformed into facilities other than tourism. If you want to continue tourism, consideration should be taken to change the utilization of destinations, trying to target new markets, repositioning tourist attractions to other forms of more interesting. If the Destination Management has sufficient capital, or there are private parties interested in conducting restraint such as building man-made attractions, such an undertaking can be done, but all efforts have not guaranteed the rejuvenation.

Furthermore, the concept is used to review the development stage of tourist destinations in Tri ning Danu. However, in this paper, the profile of the development of DTW Tri ning Danu is not only using TALCS but also by adding the variable of tourism capital. Based on the previous exposure, obtained profile about the distribution of capital in Tri ning Danu as follows:

TABLE I

DISTRIBUTION OF TOURISM CAPITAL IN TRI NING DANU

\begin{tabular}{|c|c|c|c|c|c|}
\hline \multirow{2}{*}{ Lake } & \multicolumn{5}{|c|}{ Tourism Capital } \\
\hline & Physical & Social & Cultural & Economic & Symbolic \\
\hline Beratan & $\overline{0}$ & $\overline{0}$ & $\bar{Q}$ & $\bar{\square}$ & $\overline{0}$ \\
\hline Buyan & Q & & Q & & \\
\hline Tamblingan & 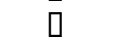 & & 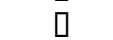 & $\square$ & \\
\hline
\end{tabular}

Based on distribution and composition, it shows that Lake Beratan is the most complete capital because the five types of capital are environmental, social, cultural, economic, and symbolic owned by the local community. For Lake Buyan based its tourism capital is said to be lacking because it only has environmental and cultural capital only. As for Lake Tamblingan because it has three types of capital, namely environment, culture, and economy, so it can be said to have moderate tourism capital

Furthermore, if reviewing the conception of TALCS and tourism capital owned by Tri ning Danu, the following three lake developments are considered: 


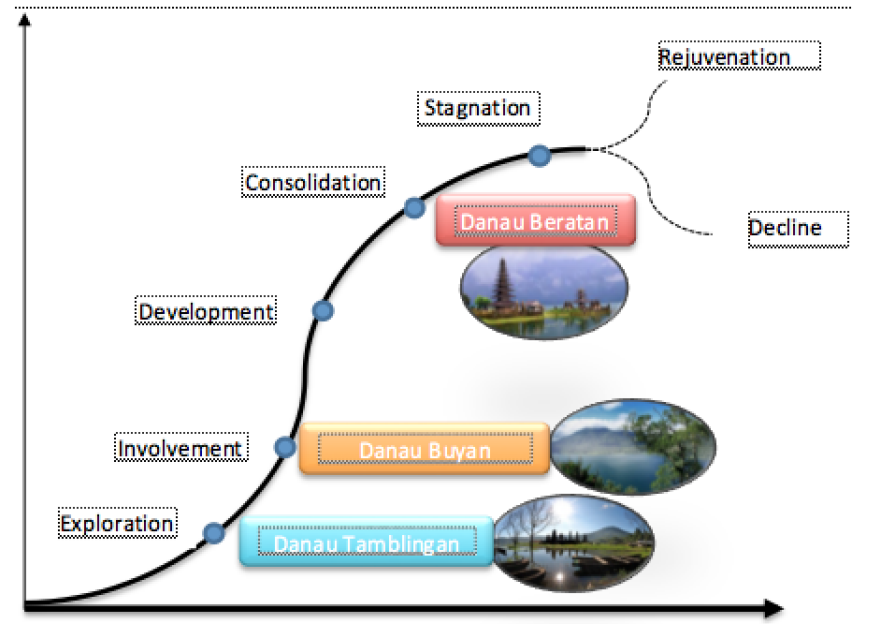

Fig. 1. The Stage of Tourism Development in Tri ning Danu.

1) Consolidation stage at Lake Beratan.

The tourism sector shows the dominance in the economic structure of Lake Beratan, and there is a tendency of the dominance of international network to strengthen its role in this region. Visits of tourists still show a fairly positive increase but there has been a price competition among similar companies in the tourism industry. The role of the Tabanan Regency Government is starting to decrease, so consolidation is needed to reorganize and balance the roles and duties of government, the private sector, and local communities. The position of local communities in the destination is relatively strong because of the relatively controlled four types of capital, namely: the physical, cultural, social, and economic environment. The control of these capital causes local people to have the most important tourism capital, that is symbolic tourism capital.

2) Involvement stage at Lake Buyan.

A small part of the local community takes the initiative by providing various services to tourists who are beginning to show signs of improvement over periods. Communities and local government have started to socialize or advertising on a limited scale, on a season or month or a particular day for example on school holidays tourists visit in large numbers, in this condition the local government took the initiative to build tourism infrastructure but still in scale and limited number. For Lake Buyan based its tourism capital is said to be lacking because it only has environmental and cultural capital only. While for tourism economic capital is considered not owned because there is no tourism business owned by local communities and management of tourism is still controlled by external parties.

3) Exploration stage at Lake Tamblingan.

Lake Tamblingan has the potential to be developed into an attraction or a tourist destination because it is supported by natural beauty that is still natural, natural tourist attraction is still very original, on the other side there has been tourist visits in small quantities and they are still free to meet and communicate and interact with the locals. This characteristic is enough to be used as the reason for the development of a region into a destination or a tourist attraction. Although the stage of its tourism development is the lowest among the other Tri ning Danu, it is attractive to the distribution and composition of capital owned by the medium category because it has environmental, cultural and economic capital. This makes Lake Tamblingan superior to Lake Buyan. The stage of its tourism development is said to be lower than the other two due to tourism practices at Lake Tamblingan done more recently. But today the phenomenon of tourism is developing relatively rapidly, so it is not impossible in the near future its position will surpass Lake Buyan.

\section{CONCLUSION}

The study of lake-based tourism phenomenon is still very rare, especially in Indonesia. This paper attempts to fill the void, focusing on the study of the stages of the development of the lake tourism in the Bedugul Tourist Destination Area. It is hoped that this effort will be a trigger for other studies related to lake-based tourism. This research still focuses on the stages of the development of lake-based tourism by using an evolutionary approach that combines TALCS conception and tourism capital as its analysis. In the future, further study is needed on the more integrated tourism development model related to Tri ning Danu.

\section{REFERENCES}

[1] Bourdieu, Pierre. 1996. Distinction : A Social Critique of The Judgement of Taste. Cetakanke-8, translated by Richard Nice. Cambridge: Harvard University Press.

[2] Butler, R.W. 1980. The Concept of The Tourist Area Life-Cycle of Evolution: Implications For Management Of Resources. Canadian Geographer 24 (1), 5-12. 